\title{
Long-term outcome of early stage prostate cancer treated with brachytherapy analysis after a mean follow-up of 7 years
}

\author{
Weigang Yan ${ }^{1}$, Jian Chen ${ }^{1}$, Yi Zhou', Zhien Zhou', Zhipeng Mai ${ }^{1}$, Zhigang Ji', Hanzhong $\mathrm{Li}^{\text {* }}$ and Fuquan Zhang ${ }^{2}$
}

\begin{abstract}
Purpose: To investigate the long-term efficacy of ${ }^{125}$ brachytherapy in early-stage prostate cancer and to identify correlating factors.

Methods: This study included 117 cases of early stage prostate cancer. The patients ranged in age from 51 to 84 years, with a mean of 73 years. The features of the study population were as follows: the PSA ranged from 0.4 to $47.6 \mathrm{ng} / \mathrm{ml}$ (median, 14.7); the Gleason score ranged from 4 to 9 (mean, 6.4); the clinical stage ranged from T1b to T2c; and the positive biopsy rate ranged from 0.08 to 1.0 (mean, 0.45). The mean D90 was 142 Gy and ranged from 106 Gy to $170 \mathrm{~Gy}$. The numbers of low-risk, intermediate-risk and high-risk prostate cancer cases were 22, 29 and 66, respectively. The biochemical no evidence of disease (bNED) rate and overall survival were recorded. Factors that correlated with the outcomes were evaluated.

Results: With a mean follow up of 84 months, 33 cases had biochemical recurrence, with a bNED rate of 72\%. The overall survival rate was $90 \%$, and the cancer-specific survival rate was $97 \%$. The bNED rates in the low-risk, intermediate-risk and high-risk groups were $86 \%, 79 \%$ and $64 \%$, respectively $(P=0.040)$. The patients with PSA $<20 \mathrm{ng} / \mathrm{ml}$, a positive biopsy rate lower than 0.5 , and D90 $\geq 140$ Gy had lower biochemical recurrence $(P=0.028$, $0.006,0.009$, respectively).
\end{abstract}

Conclusions: The long-term efficacy of ${ }^{125}$ I brachytherapy in early stage prostate cancer was shown. bNED is related to risk stratification, PSA level, positive biopsy rate and D90.

Keywords: Prostate cancer; Brachytherapy; Biochemical no evidence of disease; Overall survival

\section{Introduction}

Brachytherapy is a radical treatment that can achieve the same effect as radical prostatectomy and external beam radiotherapy (EBRT) (Nag et al. 1999; Davis et al. 2012; Park et al. 2013). However, studies of the long-term clinical outcome in large cohorts of prostate cancer patients treated with brachytherapy from mainland China are lacking. A total of 564 patients with localized prostate cancer were treated with brachytherapy from December 2003 to August 2013 in Peking Union Medical College Hospital. Among the 138 patients who underwent brachytherapy before December 2007, 117 patients were followed.

\footnotetext{
* Correspondence: ywgemailbox@sina.com

${ }^{1}$ Department of Urology, Peking Union Medical College Hospital, Chinese Academy of Medical Sciences, Beijing 100730, China

Full list of author information is available at the end of the article
}

\section{Materials and methods}

\section{Patient characteristics}

A total of 117 consecutive patients with localized prostate cancer treated with brachytherapy were enrolled in this retrospective analysis (Table 1). The mean age of the studied cohort was 73 years, ranging from 51 years to 84 years. All of the patients were diagnosed with prostate cancer based on transperineal ultrasound-guided prostate biopsy. The mean PSA level was $14.7 \mathrm{ng} / \mathrm{ml}$, ranging from $0.4 \mathrm{ng} / \mathrm{ml}$ to $47.6 \mathrm{ng} / \mathrm{ml}$. The Gleason score ranged from 4 to 9 , with a median of 6 . The clinical stage ranged from $\mathrm{T} 1 \mathrm{~b}$ to $\mathrm{T} 2 \mathrm{c}$. The mean prostate volume was $31 \mathrm{ml}$, ranging from $13 \mathrm{ml}$ to $69 \mathrm{ml}$. The mean percent positive core (PPC) was $45 \%$, ranging from $8 \%$ to $100 \%$. In each patient, pretreatment CT or MRI of the thorax/ 


\section{Table 1 Patient characteristics}

\begin{tabular}{|c|c|}
\hline Parameters & $\mathrm{N}(\%)$ \\
\hline \multicolumn{2}{|l|}{ Age (years) } \\
\hline $51-70$ & $36(31)$ \\
\hline $71-75$ & $40(34)$ \\
\hline $76-84$ & $41(35)$ \\
\hline \multicolumn{2}{|l|}{ Clinical stage } \\
\hline $\mathrm{T} 1 \mathrm{~b}$ & $1(1)$ \\
\hline T1c & $18(15)$ \\
\hline T2a & $27(23)$ \\
\hline $\mathrm{T} 2 \mathrm{~b}$ & $21(18)$ \\
\hline $\mathrm{T} 2 \mathrm{C}$ & $50(43)$ \\
\hline \multicolumn{2}{|l|}{ PSA (ng/ml) } \\
\hline $0-10.0$ & $33(28)$ \\
\hline $10.1-20.0$ & $42(36)$ \\
\hline$>20.0$ & $42(36)$ \\
\hline \multicolumn{2}{|c|}{ Gleason score } \\
\hline 4 & $3(3)$ \\
\hline 5 & $13(11)$ \\
\hline 6 & $53(45)$ \\
\hline 7 & $31(26)$ \\
\hline 8 & $12(10)$ \\
\hline 9 & $5(4)$ \\
\hline \multicolumn{2}{|c|}{ Prostate volume } \\
\hline$\geq 30 \mathrm{ml}$ & $53(45)$ \\
\hline$<30 \mathrm{ml}$ & $64(55)$ \\
\hline \multicolumn{2}{|l|}{ PPC } \\
\hline$<0.5$ & $69(59)$ \\
\hline$\geq 0.5$ & $48(41)$ \\
\hline \multicolumn{2}{|l|}{ EBRT } \\
\hline Yes & $6(5)$ \\
\hline No & $111(95)$ \\
\hline \multicolumn{2}{|l|}{ D 90} \\
\hline$\geq 140$ & $78(70)$ \\
\hline$<140$ & $33(30)$ \\
\hline
\end{tabular}

abdomen/pelvis and a bone scan showed no seminal vesicle or pelvic lymph node involvement and no distant metastasis. Patients were clinically staged based on a medical history and physical and imaging examinations.

The risk stratification of the study population complied with the standard provided by NCCN updated in 2012 . The low-risk subgroup with a PSA $\leq 10.0 \mathrm{ng} / \mathrm{ml}$, a Gleason score of 2-6 and Stage T1-T2a included 22 patients; 3 patients in this subgroup received neo-adjuvant androgen deprivation therapy (ADT) to shrink prostate before brachytherapy, but the other 19 patients underwent brachytherapy alone. The intermediate-risk subgroup with $10 \mathrm{ng} / \mathrm{ml}<$ PSA $\leq 20.0 \mathrm{ng} / \mathrm{ml}$, a Gleason score of 7 and Stage T2b included 29 patients, all of whom underwent 6 months of ADT after brachytherapy. The highrisk group was defined as those with PSA $\geq 20.0 \mathrm{ng} / \mathrm{ml}$, a Gleason score of 8-10 and Stage T2c. ADT consisted of a gonadotropin-releasing hormone agonist with an antiandrogen. For the intermediate-risk patients, ADT was administered for 6 months, during 3 months of which, it was administered neoadjuvantly. For the high-risk patients, ADT was administered from the 6-month time point to the 3-year time point, during 3 months of which, it was administered neoadjuvantly. Six of the high-risk patients were combined with EBRT (Table 2).

\section{Treatment}

Three to 7 days before implantation, patients underwent a volumetric study of the prostate performed by transrectal ultrasound (SONOLINE Adara SLC Ultrasound; Siemens, Munich, Germany). Brachytherapy was performed in patients under epidural anesthesia. ${ }^{125}$ I seeds were accurately introduced in preplanned positions by a brachytherapy stepping unit (Computerized Medical System Inc., St. Louis, MO) with a standard $0.5 \mathrm{~cm}$ brachytherapy template placed over the perineum. ${ }^{125} \mathrm{I}$ implants were generally prescribed to 145 Gy for monotherapy and 110 Gy was used in combination with EBRT. EBRT was delivered with intensity-modulated radiation therapy.

The intraoperative planning time ranged from 20 to 35 minutes (mean $26 \mathrm{~min}$ ), and the implantation time ranged from 24 to 48 minutes (mean $31 \mathrm{~min}$ ). Using real-time US guidance, the radioactive seeds were then placed through the needles with a Mick applicator. The implanted seeds were of particle activity ranging from $0.30 \mathrm{mCi}$ to 0.50 $\mathrm{mCi}$ each, with a total activity of $15 \mathrm{mCi}$ to $43.2 \mathrm{mCi}$ for each patient, (mean $25.1 \mathrm{mCi}$ ). The $\mathrm{D} 90$ of monotherapy ranged from 132 Gy to $170 \mathrm{~Gy}$, and that of combination therapy with EBRT ranged from 106 Gy to $113 \mathrm{~Gy}$, with a mean D90 of $142 \mathrm{~Gy}$.

A KUB was scheduled after the procedure to check the distribution of the implanted seeds. The urinary catheter was withdrawn 1 to 3 days after the procedure. Four to 6 weeks after the implantation, dosimetric analysis was performed by computed tomography (CT). The D90 was calculated in each patient.

Table 2 Risk groups and treatment method

\begin{tabular}{lllll}
\hline Risk group & $\begin{array}{l}\text { Patient } \\
\text { number }\end{array}$ & $\begin{array}{l}\text { Brachytherapy } \\
\text { only }\end{array}$ & $\begin{array}{l}\text { Brachytherapy } \\
\text { + ADT }\end{array}$ & $\begin{array}{l}\text { Brachytherapy } \\
\text { + EBRT + ADT }\end{array}$ \\
\hline Low & 22 & 19 & 3 & 0 \\
Intermediate & 29 & 0 & 29 & 0 \\
High & 66 & 0 & 60 & 6 \\
\hline
\end{tabular}




\section{Follow-up}

The patients were monitored based on serum PSA measurement monthly during the first 3 months after implantation and at 3-month intervals thereafter. If the PSA level was stable, routine follow-up was scheduled every 6 months for 2 years after the implantation. Complications were recorded. The endpoints of this study included biochemical no evidence of disease (bNED) and overall survival. Biochemical failure was determined using the American Society of Radiation Oncology "Phoenix" definition, based on the current nadir plus $2 \mathrm{ng} / \mathrm{ml}$.

Genitourinary toxicities for hematuria, retention, and incontinence and gastrointestinal toxicities were reported using the Radiation Therapy Oncology Group (RTOG)/ European Organisation for Research and Treatment of Cancer (EORTC) long-term toxicity scale.

\section{Statistical analysis}

Survival curves were generated using the Kaplan-Meier method. Log-rank analysis was used for comparisons of outcomes in various subgroups. Proportions were compared with the use of chi-square tests. For all tests, a value of $\mathrm{p} \leq 0.05$ was considered statistically significant. Statistical analysis was performed using SPSS version 19.0 (SPSS Inc., Chicago, IL).

The enrolled patients consented to the study, which was approved by the ethics research committee of the Peking Union Medical College Hospital, Chinese Academy of Medical Science.

\section{Results}

With a mean follow-up of 84 months and a median follow-up of 86 months (19-114 months), the nadir PSA level ranged from 0 to $1.27 \mathrm{ng} / \mathrm{ml}$ (median $0.01 \mathrm{ng} / \mathrm{ml}$ ). Thirty-three patients had biochemical recurrence, producing a bNED rate of $72 \%$ (Figure 1). Twelve patients died, 4 of them from prostate cancer, for an overall survival rate of $90 \%$ (Figure 2) and a disease-specific survival rate of $97 \%$.

Among the 22 cases of low-risk prostate cancer, 3 experienced biochemical recurrence at 11 months, 48 months and 73 months after brachytherapy; the bNED rate was $86 \%$. No patient died, and the overall survival rate was $100 \%$ for low-risk patients. Six of the 29 patients with intermediate-risk disease had biochemical recurrence at 7 months, 19 months, 30 months, 34 months, 37 months and 60 months after the procedure; the bNED rate was $79 \%$. Three deaths occurred because of lung cancer, myocardial infarction and pancreatic cancer at 53 months, 95 months and 109 months after the procedure, producing an overall survival rate of $90 \%$ among the intermediaterisk patients. When combined, the low- and intermediaterisk patients had a bNED rate of $82 \%$ and an overall survival

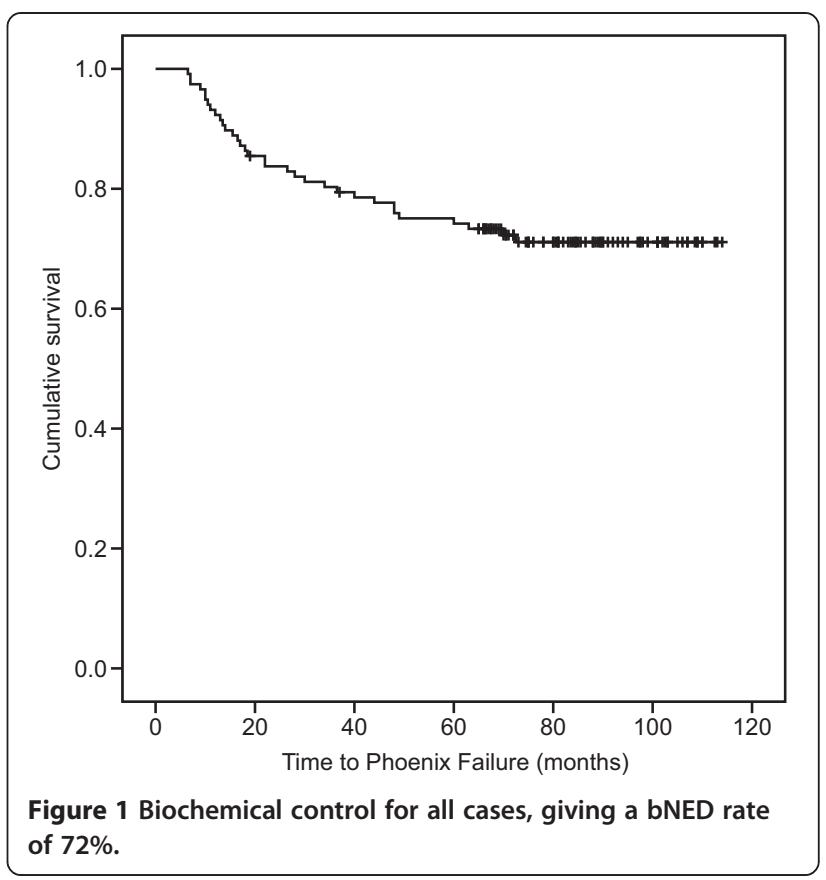

rate of $94 \%$. Of the 66 high-risk patients, 24 biochemical recurrences were observed between 7 and 70 months after brachytherapy (16 occurred within a year). The bNED rate of this group was $64 \%$. Nine deaths occurred, 4 of which were due to prostate cancer, at 41 months, 41 months, 86 months and 89 months after the procedure. The other 5 cases died from pancreatic cancer, lung cancer, cerebral hemorrhage, pneumonia and renal failure at 19 months, 35 months, 56 months, 81 months and 101 months after

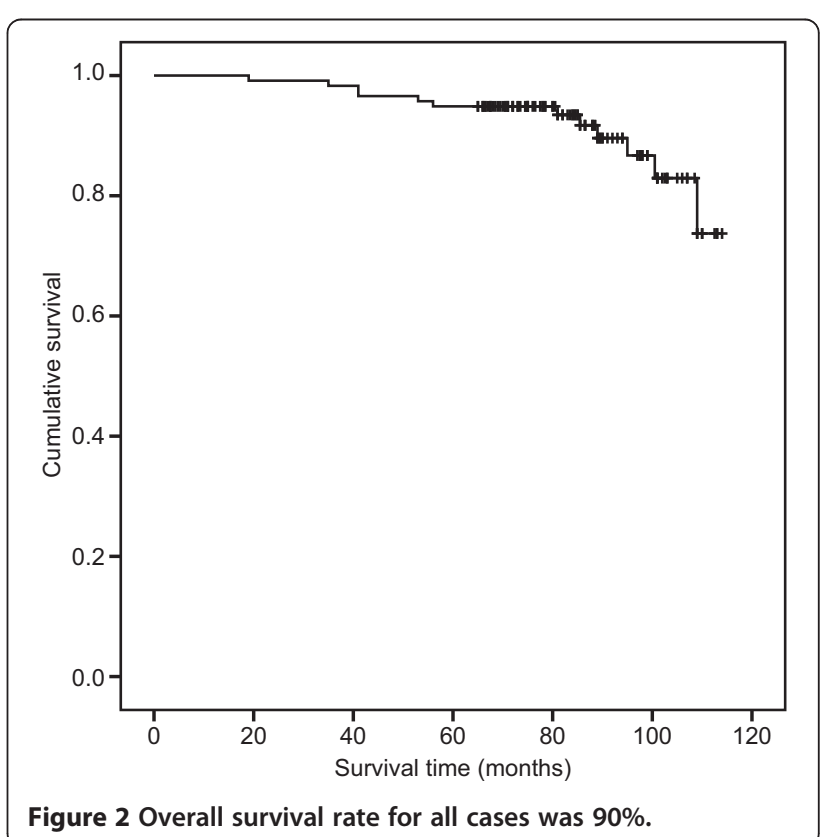


the procedure. The overall survival rate of the combined group was $86 \%$. EBRT and ADT were prescribed for patients who biochemically relapsed during the follow-up period. The biochemical control results of the three subgroups were significantly different $(\mathrm{P}=0.040)$ (Figure 3 ); however, the overall survival rate of the three groups demonstrated no significant difference $(\mathrm{P}=0.189)$.

bNED was also examined among the different subgroups (Table 3). Patients whose PPC was lower than $50 \%$ had a lower biochemical recurrence likelihood than those whose $\mathrm{PPC}$ was higher than $50 \%(\mathrm{P}=0.006)$ (Figure 4). Patients who received a D90 higher than 140 Gy had better biochemical control than those who received a D90 lower than 140 Gy $(P=0.009)$ (Figure 5). Patients with a PSA level lower than $20 \mathrm{ng} / \mathrm{ml}$ had a lower biochemical recurrence rate than those with a PSA level higher than $20 \mathrm{ng} / \mathrm{ml}$ $(\mathrm{P}=0.028)$. The bNED rate did not significantly differ between clinical stage $\mathrm{T} 1 \mathrm{~b}-\mathrm{T} 2 \mathrm{~b}$ and $\mathrm{T} 2 \mathrm{c}(\mathrm{P}=0.094)$. Additionally, no significant differences in biochemical relapse were observed in the subgroups with a Gleason score higher or lower than 7 or the subgroups with a prostate volume larger or smaller than $30 \mathrm{ml}(\mathrm{P}=0.137,0.104)$.

RTOG/EORTC graded genitourinary and gastrointestinal toxicities were shown in Table 4. Urinary retention was observed in 11 patients after brachytherapy (9.4\%). After urinary catheterization for 1 week, 10 patients were cured. One patient was cured with transurethral prostatectomy because of recurrent episodes of urinary retention. Of the $62 \%(72 / 117)$ potent patients before treatment, $67 \%$ (48/72) remained potent. No serious complications such as prostatic rectal fistula were observed.

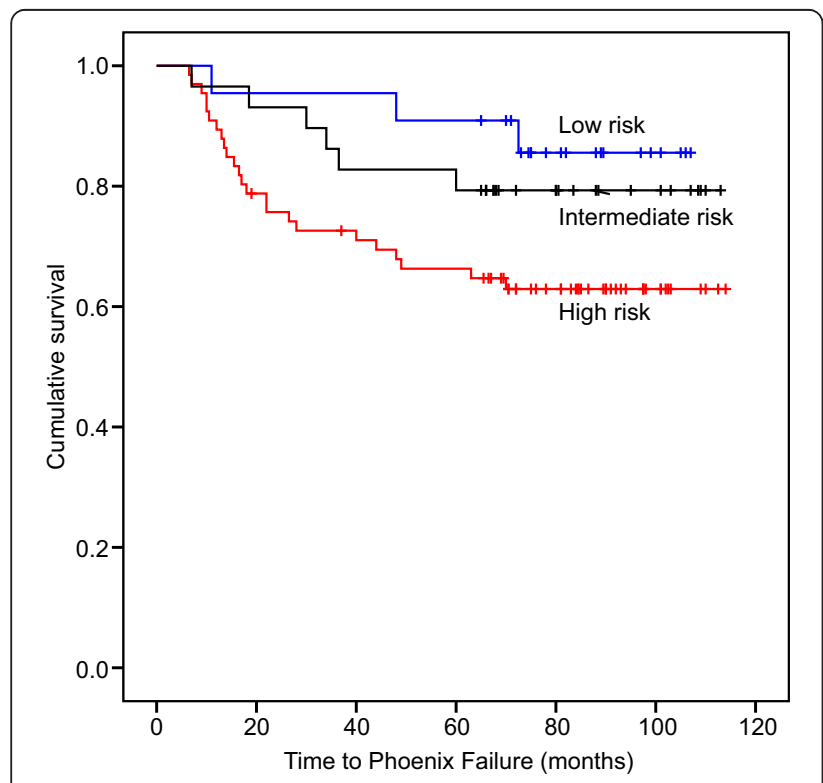

Figure 3 The bNED rate in low-risk, intermediate - risk and high-risk groups were $86 \%, 79 \%$ and $64 \%$ respectively $(P=0.040)$.
Table 3 bNED rate due to various factors

\begin{tabular}{|c|c|}
\hline Factors & N (bNED rate, \%) \\
\hline \multicolumn{2}{|l|}{ PSA } \\
\hline $0-20.0 \mathrm{ng} / \mathrm{ml}$ & $79(59 / 76)$ \\
\hline$>20.0 \mathrm{ng} / \mathrm{ml}$ & $60(25 / 42)$ \\
\hline $\mathrm{p}$-value & 0.028 \\
\hline \multicolumn{2}{|l|}{ Gleason score } \\
\hline$<7$ & $77(53 / 69)$ \\
\hline$\geq 7$ & $65(31 / 48)$ \\
\hline $\mathrm{p}$-value & 0.137 \\
\hline \multicolumn{2}{|l|}{ Clinical stage } \\
\hline $\mathrm{T} 1 \mathrm{~b}-\mathrm{T} 2 \mathrm{~b}$ & $78(52 / 67)$ \\
\hline $\mathrm{T} 2 \mathrm{C}$ & $64(32 / 50)$ \\
\hline$p$-value & 0.094 \\
\hline \multicolumn{2}{|l|}{ Prostate volume } \\
\hline$\geq 30 \mathrm{ml}$ & $74(40 / 54)$ \\
\hline$<30 \mathrm{ml}$ & $70(44 / 63)$ \\
\hline $\mathrm{p}$-value & 0.740 \\
\hline \multicolumn{2}{|l|}{ PPC } \\
\hline$<50 \%$ & $81(56 / 69)$ \\
\hline$\geq 50 \%$ & $58(28 / 48)$ \\
\hline $\mathrm{p}$-value & 0.006 \\
\hline \multicolumn{2}{|l|}{ D 90} \\
\hline$\geq 140 \mathrm{~Gy}$ & $81(63 / 78)$ \\
\hline$<140$ Gy & $52(17 / 33)$ \\
\hline $\mathrm{p}$-value & 0.009 \\
\hline
\end{tabular}

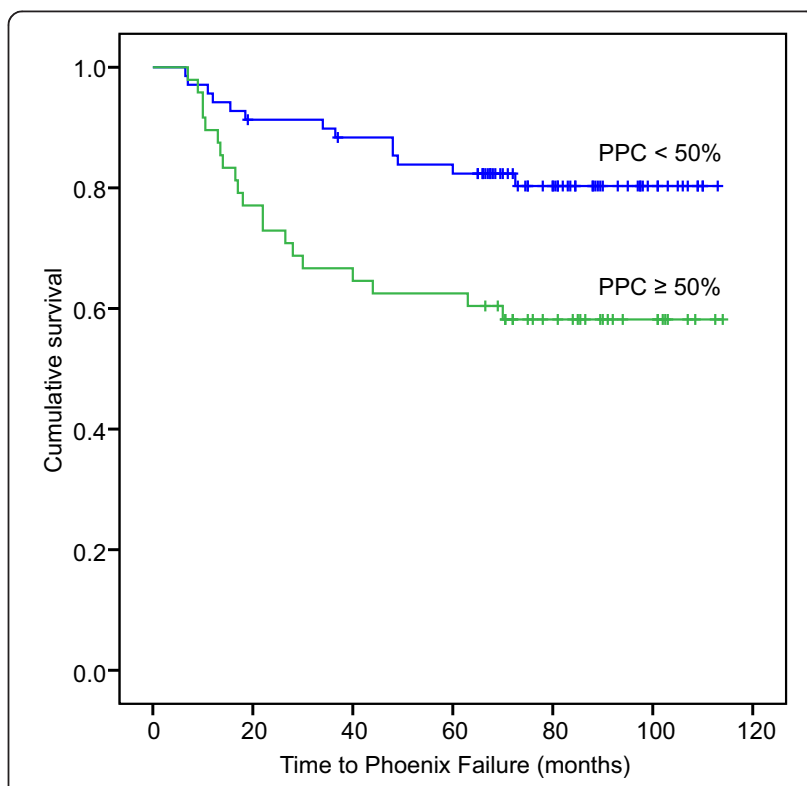

Figure 4 Patients whose PPC $<50 \%$ had less biochemical recurrence likelihood than those whose $P P C \geq 50 \%(P=0.006)$. 


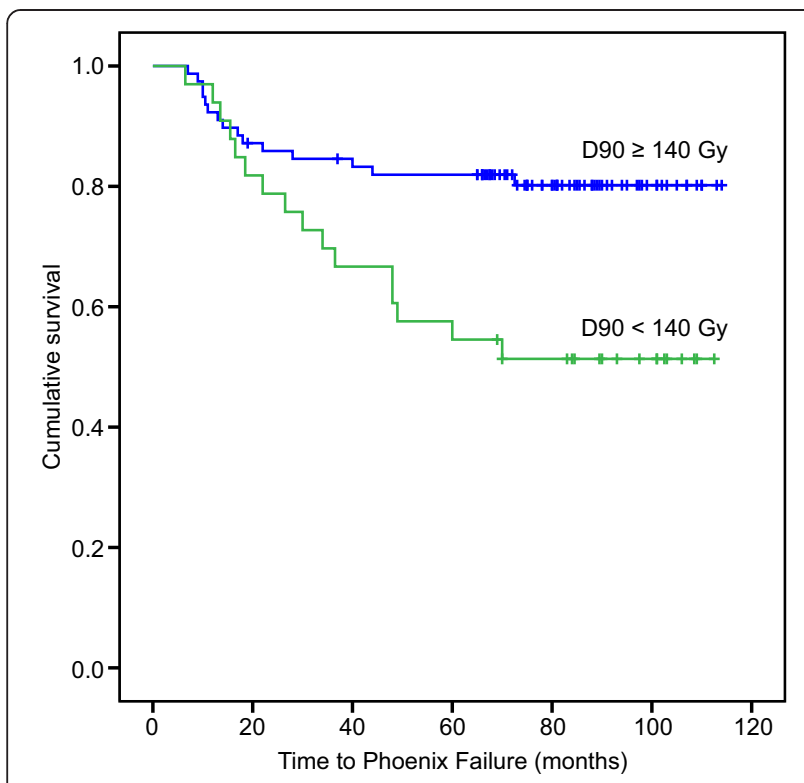

Figure 5 Patients whose $\mathrm{D} 90 \geq 140$ Gy had better biochemical control than those $\mathrm{D} 90<140 \mathrm{~Gy}(\mathrm{P}=0.009)$.

\section{Discussion}

The radical effect of brachytherapy for localized prostate cancer has been confirmed worldwide. Since the first introduction of ${ }^{125} \mathrm{I}$ brachytherapy from western countries to China occurred more than a decade ago, few centers have reported long-term outcomes. To our knowledge, this is one of the largest cohort of prostate cancer patients treated with brachytherapy with the longest follow-up from mainland China reported to date, though the results represent our early experience.

The indication for brachytherapy suggested by the American Brachytherapy Society (ABS) is localized prostate cancer (Nag et al. 1999; Davis et al. 2012). Brachytherapy monotherapy can achieve radical effects for localized low-risk prostate cancer. However, for intermediate- and high-risk patients, EBRT or ADT should be added. Although patients may benefit from the combined therapy in terms of overall survival rate, they also experience

\begin{tabular}{|c|c|c|c|c|}
\hline Toxicity & Grage $0-1$ & Grade 2 & Grade 3 & Grade 4 \\
\hline \multicolumn{5}{|l|}{ Genitourinary } \\
\hline Retention & 106 & 10 & 1 & 0 \\
\hline Hematuria & 103 & 14 & 0 & 0 \\
\hline Incontinence & 113 & 4 & 0 & 0 \\
\hline \multicolumn{5}{|l|}{ Gastrointestinal } \\
\hline Proctitis & 109 & 6 & 2 & 0 \\
\hline Rectal bleeding & 108 & 8 & 1 & 0 \\
\hline
\end{tabular}

increased economic burden, additional complications, and greater inconvenience to their daily lives. For these reasons, the latest $\mathrm{ABS}$ guidelines suggest that brachytherapy monotherapy can also be applied in intermediate-risk localized prostate cancer (Davis et al. 2012). Although there is solid evidence indicating that brachytherapy monotherapy achieves the same curative effect as brachytherapy combined with EBRT (Blasko et al. 2000), many clinical centers have added ADT or EBRT routinely for intermediaterisk localized prostate cancer patients (Davis et al. 2012). In our study population, we prescribed 6 months of ADT in intermediate-risk patients. We initially planned to add EBRT for high-risk patients before or after brachytherapy. However, due to the serious urinary track irritation and rectal irritation symptoms associated with the first 6 patients and the relatively optimistic outcomes from other clinics with high-risk patients treated with brachytherapy monotherapy (Merrick et al. 2003; Marshall et al. 2014), we did not perform EBRT in the high-risk patients and opted for brachytherapy monotherapy instead.

Regarding the combination with ADT, we refer to the experience of EBRT combined with ADT: long-term (23 years) ADT can improve the biochemical relapse-free survival rate and the overall survival rate of high-risk prostate cancer (Bolla et al. 2009; Hanks et al. 2003). In our study, all of the high-risk patients received ADT, 39 of whom underwent ADT for more than 2 years; ADT in the other 27 cases was administered for less than 2 years for a variety of reasons. Marshall et al.'s study reported that ADT had a benefit in reducing the biochemical recurrence rate after brachytherapy (Marshall et al. 2014). However, Stock has stated that ADT improves FBF only in the setting of lower doses, i.e., a biological effective dose $<220$ Gy (Stock et al. 2013). The benefit of ADT may primarily be as an enhancer of local control, explaining why high radiation doses can compensate for its absence. Therefore, we prescribed ADT for all highrisk and intermediate-risk patients. Regarding the lowrisk patients, the neoadjuvant endocrine therapy was aimed at reducing the volume of the prostate to reduce the interference of the pubic arch.

For early stage prostate cancer, a radical effect can be achieved with brachytherapy, EBRT, brachytherapy combined with EBRT and radical prostatectomy (Davis et al. 2012; Aizer et al. 2009; Kupelian et al. 2004), with similar 5-year biochemical recurrence-free survival rates (Kupelian et al. 2004). Patients can obtain a satisfactory curative effect despite the risk category they fall in (Marshall et al. 2014). Marshall et al.'s analyzed 2495 patients with localized prostate cancer. The 12-year biochemical recurrence-free survival rate was $83 \%$ (90\% for the low-risk group, $84 \%$ for the intermediate-risk group and $64 \%$ for the high-risk group). The cancer-specific survival rate was $95 \%$, and the overall survival rate was 
70\%. A meta-analysis performed by Merrick et al. (2003) showed different clinical outcomes among different centers. The biochemical recurrence-free survival rate for low-, intermediate- and high-risk patients 3 to 7 years after brachytherapy ranged from 85\%-96\%, 74\%-97\% and $38 \%-82 \%$, respectively. With a 7 -year follow-up, our study population had an overall biochemical recurrencefree survival rate of $72 \%$ ( $86 \%, 79 \%$ and $64 \%$ for the low-, intermediate- and high-risk patients, respectively). The cancer-specific survival rate was $97 \%$, and the overall survival rate was $90 \%$. Compared with previous studies, we obtained similar results in the intermediate-risk patients and relatively poor outcomes in the low-risk patients. We believe the reasons for these findings are as follows. 1 . The study enrolled a relatively small study cohort. 2 . The study administered a low therapeutic radiation dose. Of the 111 patients in our cohort treated with brachytherapy alone, 33 cases had a D90<140 Gy, among which 17 patients had biochemical relapse. The biochemical relapse rate was higher in patients with a D90 $<140$ Gy than in those with a D $90 \geq 140 \mathrm{~Gy}$, indicating that the therapeutic radiation dose is related to the cure effect (Stone et al. 2005). 3. In our center, the ${ }^{125}$ I seeds were implanted with a Mick applicator, rather than using a seed strand, thus resulting in a relatively reduction of therapeutic radiation due to seed migration (Lin et al. 2007). However, the seed strand method has not yet been introduced to mainland China.

In general, the factors affecting the effect of brachytherapy can be divided into preoperative, operative and postoperative. The preoperative factors are the PSA level (Potters et al. 2008), Gleason score (Sylvester et al. 2011), risk stratification (Taira et al. 2010), PPC (Taira et al. 2011) and prostate volume (Le et al. 2013). The operative factors are therapeutic radiation dose (Stone et al. 2005) and the proficiency of implantation (Zelefsky et al. 2007), and the postoperative factor is combination with ADT (Marshall et al. 2014) or EBRT (Davis et al. 2012). The results indicated that biochemical recurrence rates differ significantly among groups of patients with different risk factors, showing compliance with results from other centers. However, the overall survival rates among the three groups were of not significantly different, most likely due to our relatively small sample. Based on the analysis of the risk factors, PSA $\geq 20 \mathrm{ng} / \mathrm{ml}, \mathrm{PPC} \geq 50 \%$, and a D $90<140$ Gy were associated with a high biochemical recurrence rate, as suggested by previous studies (Stone et al. 2005; Potters et al. 2008; Taira et al. 2011). Interestingly, we discovered that PPC had a more obvious relationship with the biochemical relapse rate than other factors such as clinical stage or risk stratification. Researchers have also suggested that PPC, being an independent predictive factor, plays a significant role in predicting the biochemical relapse-free survival rate and the overall survival rate in patients undergoing radical prostatectomy (Briganti et al.
2007), EBRT (Spalding et al. 2007) and brachytherapy (Urani et al. 2007).

Urinary retention is the commonly observed complication after brachytherapy for prostate cancer. However, the majority of cases can be improved by urinary catheterization combined with alpha blockers; only a few require TURP intervention. TURP should be delayed 6 months after brachytherapy to avoid urinary incontinence. One of the patients in our study population who had repeated recurrence of urinary retention underwent TURP, with subsequent symptom improvement. Prostate rectal fistula has a relatively low incidence, lower than $1 \%$; however, with a difficult intervention, these cases often require fecal and urinary diversion (Elebrezze \& Medich 2003). No prostate rectal fistula was observed in our patients because we were conservative about the radiation dose delivered to the prostate area adjacent to the rectum. The reduced local radiation dose might inevitably have led to relatively poorer treatment effect.

In conclusion, we believe that ${ }^{125} \mathrm{I}$ brachytherapy for prostate cancer is an effective, less traumatic method with fewer complications than radical methods of prostate cancer treatment. Further randomized controlled studies with larger samples from multiple centers are needed to verify the efficacy and complications of this method in mainland China.

\section{Ethical standards}

We stated that the study has been approved by the appropriate ethics committee and has therefore been performed in accordance with the ethical standards laid down in the 1964 Declaration of Helsinki and its later amendments. We also stated that all persons gave their informed consent prior to their inclusion in the study.

\section{Competing interest}

The authors have no conflicts of interest with any institutions or products. No financial support was received by any author.

\section{Authors' contributions}

WY Project development, Data Collection, Manuscript writing. JC Data Collection. YZ Data analysis. ZZ Data Collection. ZM Data Collection. ZJ Manuscript editing. HL Project development, Manuscript editing, Manuscript writing. FZ Manuscript editing. All authors read and approved the final manuscript.

\section{Author details}

${ }^{1}$ Department of Urology, Peking Union Medical College Hospital, Chinese Academy of Medical Sciences, Beijing 100730, China. ${ }^{2}$ Department of Radiation Oncology, Peking Union Medical College Hospital, Chinese Academy of Medical Sciences, Beijing, China.

Received: 11 April 2014 Accepted: 7 July 2014

Published: 15 July 2014

\section{References}

Aizer AA, Yu JB, Colberg JW, McKeon AM, Decker RH, Peschel RE (2009) Radical prostatectomy vs. intensity-modulated radiation therapy in the management of localized prostate adenocarcinoma. Radiother Oncol 93(2):185-191 
Blasko JC, Grimm PD, Sylvester JE, Cavanagh W (2000) The role of external beam radiotherapy with 1-125/Pd-103 brachytherapy for prostate carcinoma. Radiother Oncol 57(3):273-278

Bolla M, de Reijke TM, Van Tienhoven G, Van den Bergh AC, Oddens J, Poortmans PM, Gez E, Kil P, Akdas A, Soete G, Kariakine O, van der Steen-Banasik EM, Musat E, Piérart M, Mauer ME, Collette L, EORTC Radiation Oncology Group and Genito-Urinary Tract Cancer Group (2009) Duration of androgen suppression in the treatment of prostate cancer. N Engl J Med 360(24):2516-2527

Briganti A, Chun FK, Hutterer GC, Gallina A, Shariat SF, Salonia A, Scattoni V, Valiquette L, Montorsi F, Rigatti P, Graefen M, Huland H, Karakiewicz PI (2007) Systematic assessment of the ability of the number and percentage of positive biopsy cores to predict pathologic stage and biochemical recurrence after radical prostatectomy. Eur Urol 52(3):733-743

Davis BJ, Horwitz EM, Lee WR, Crook JM, Stock RG, Merrick GS, Butler WM, Grimm PD, Stone NN, Potters L, Zietman AL, Zelefsky MJ, American Brachytherapy Society (2012) American Brachytherapy Society consensus guidelines for transrectal ultrasound-guided permanent prostate. Brachytherapy 11(1):6-19

Elebrezze JP, Medich DS (2003) Rectal ulceration as a result of prostatic brachytherapy: a new clinical problem. Dis Colon Rectum 46(9):1277-1279

Hanks GE, Pajak TF, Porter A, Grignon D, Brereton H, Venkatesan V, Horwitz EM, Lawton C, Rosenthal SA, Sandler HM, Shipley WU, Radiation Therapy Oncology Group (2003) Phase III trial of long-term adjuvant androgen deprivation after neoadjuvant hormonal cytoreduction and radiotherapy in locally advanced carcinoma of the prostate: the Radiation Therapy Oncology Group Protocol 92-02. J Clin Oncol 21(21):3972-3978

Kupelian PA, Potters L, Khuntia D, Ciezki JP, Reddy CA, Reuther AM, Carlson TP, Klein EA (2004) Radical prostatectomy, external beam radiotherapy $<72$ Gy, external beam radiotherapy $>$ or $=72 \mathrm{~Gy}$, permanent seed implantation, or combined seeds/external beam radiotherapy for stage T1-T2 prostate cancer. Int J Radiat Oncol Biol Phys 58(1):25-33

Le H, Rojas A, Alonzi R, Hughes R, Ostler P, Lowe G, Bryant L, Hoskin P (2013) The influence of prostate volume on outcome after high-dose-rate brachytherapy alone for localized prostate cancer. Int J Radiat Oncol Biol Phys 87(2):270-274

Lin K, Lee SP, Cho JS, Reiter RE, DeMarco JJ, Solberg TD (2007) Improvements in prostate brachytherapy dosimetry due to seed stranding. Brachytherapy 6(1):44-48

Marshall RA, Buckstein M, Stone NN, Stock R (2014) Treatment outcomes and morbidity following definitive brachytherapy with or without external beam radiation for the treatment of localized prostate cancer: 20-year experience at Mount Sinai Medical Center. Urol Oncol 32(1):38.e1-7

Merrick GS, Wallner KE, Butler WM (2003) Permanent interstitial brachytherapy for the management of carcinoma of the prostate gland. J Urol 169(5):1643-1652

Nag S, Beyer D, Friedland J, Grimm P, Nath R (1999) American Brachytherapy Society recommendations for transperineal permanent brachytherapy of prostate cancer. Int J Radiat Oncol Bios Phys 44(4):789-799

Park DS, Gong IH, Choi DK, Hwang JH, Shin HS, Oh JJ (2013) Radical prostatectomy versus high dose permanent prostate brachytherapy using iodine-125 seeds for patients with high risk prostate cancer: a matched cohort analysis. World J Urol 31(6):1511-1517

Potters L, Morgenstern C, Calugaru E, Fearn P, Jassal A, Presser J, Mullen E (2008) 12-year outcomes following permanent prostate brachytherapy in patients with clinically localized prostate cancer. J Urol 179(5 Suppl):S20-24

Spalding AC, Daignault S, Sandler HM, Shah RB, Pan CC, Ray ME (2007) Percent positive biopsy cores as a prognostic factor for prostate cancer treated with external beam radiation. Urology 69(5):936-940

Stock RG, Buckstein M, Liu JT, Stone NN (2013) The relative importance of hormonal therapy and biological effective dose in optimizing prostate brachytherapy treatment outcomes. BJU Int 112(2):E44-50

Stone NN, Stock RG, Unger P (2005) Intermediate term biochemical-free progression and local control following 125 iodine brachytherapy for prostate cancer. J Urol 173(3):803-807

Sylvester JE, Grimm PD, Wong J, Galbreath RW, Merrick G, Blasko JC (2011) Fifteen-year biochemical relapse-free survival, cause-specific survival, and overall survival following I (125) prostate brachytherapy in clinically localized prostate cancer: seattle experience. Int J Radiat Oncol Biol Phys 81(2):376-381

Taira AV, Merrick GS, Galbreath RW, Wallner KE, Butler WM (2010) Natural history of clinically staged low- and intermediaterisk prostate cancer treated with monotherapeutic permanent interstitial brachytherapy. Int J Radiat Oncol Biol Phys 76(2):349-354
Taira AV, Merrick GS, Butler WM, Galbreath RW, Lief J, Adamovich E, Wallner KE (2011) Long-term outcome for clinically localized prostate cancer treated with permanent interstitial brachytherapy. Int J Radiat Oncol Biol Phys 79(5):1336-1342

Urani R, Wallner K, Merrick GS, Virgin J, Orio P, True LD (2007) Optimized prostate brachytherapy minimizes the prognostic impact of percent of biopsy cores involved with adenocarcinoma. J Urol 178(5):1968-1973

Zelefsky MJ, Kuban DA, Levy LB, Potters L, Beyer DC, Blasko JC, Moran BJ, Ciezki JP, Zietman AL, Pisansky TM, Elshaikh M, Horwitz EM (2007) Multi-institutional analysis of long-term outcome for stages T1-T2 prostate cancer treated with permanent seed implantation. Int J Radiat Oncol Biol Phys 67(2):327-333

\section{doi:10.1186/2193-1801-3-357}

Cite this article as: Yan et al:: Long-term outcome of early stage prostate cancer treated with brachytherapy analysis after a mean follow-up of 7 years. SpringerPlus 2014 3:357.

\section{Submit your manuscript to a SpringerOpen ${ }^{\odot}$ journal and benefit from:}

- Convenient online submission

- Rigorous peer review

- Immediate publication on acceptance

- Open access: articles freely available online

- High visibility within the field

- Retaining the copyright to your article

Submit your next manuscript at $>$ springeropen.com 